\title{
Organização de produtos alimentícios em prateleiras de supermercado em Muritiba
}

\author{
- Bahia \\ Organization of food products on supermarket shelves in Muritiba - Bahia \\ Organización de productos alimentarios en estantes de supermercados en Muritiba - Bahia
}

Recebido: 17/05/2021 | Revisado: 27/05/2021 | Aceito: 29/05/2021 | Publicado: 02/06/2021

Daliane de Oliveira Santos Conceição Ferreira

ORCID: https://orcid.org/0000-0002-3160-6991 Instituto Federal de Educação, Ciência e Tecnologia de Baiano, Brasil E-mail: dalianedoliveira@gmail.com

Edvaldo Nascimento Costa

ORCID: https://orcid.org/0000-0002-1920-7138 Instituto Federal de Educação, Ciência e Tecnologia de Baiano, Brasil E-mail: edvaldo.costa@ifbaiano.edu.br

Estefânia Prates Rodrigues

ORCID: https://orcid.org/0000-0003-4043-6186 Universidade Estadual de Campinas, Brasil E-mail: estefaniapratesrodrigues@gmail.com

Paulo Túlio de Souza Silveira

ORCID: https://orcid.org/0000-0002-7607-0561

Universidade Estadual de Campinas, Brasil E-mail: ptssilveira@gmail.com

\begin{abstract}
Resumo
O varejo do Brasil sofre alterações a cada dia com a intenção de atender as demandas dos consumidores. Os supermercados se reinventam a cada dia para que as necessidades visuais da organização das prateleiras sejam eficientes para os clientes e com isso aumentar a sua lucratividade. O estudo foi realizado em um supermercado da cidade de Muritiba - Bahia, entre de setembro a novembro de 2019. A avaliação foi realizada de forma qualitativa, através da observação do dia a dia de um supermercado. Para a discussão das observações foi realizada busca de dados para se realizar uma discussão comparativa referente a organização e rotinas existentes no setor. Desse modo, possibilitando o melhor entendimento da natureza das variáveis a fim de desenvolver argumentos e propor soluções para a problemática. Com a observação foi verificar que os supermercados necessitam de melhorias para que os clientes possam ser atendidos de forma adequada e eficiente. Destinar um único colaborador responsável pelo setor de compras, além de colaboradores que confiram os lotes, a validade e se os produtos possuem alguma avaria, são imprescindíveis para garantir a qualidade dos produtos oferecidos, bem como garantir um menor retrabalho na organização das gôndolas do supermercado.
\end{abstract}

Palavras-chave: Supermercados; Controle de qualidade; Organização.

\begin{abstract}
The retail of Brazil undergoes changes every day with the intention of meeting the demands of consumers. Supermarkets reinvent themselves every day so that the visual needs of the organization of the shelves are efficient for customers and thereby increase their profitability. The study was carried out in a supermarket in the city of Muritiba Bahia, between September and November 2019. The evaluation was carried out in a qualitative way, through the observation of the daily life of a supermarket. For the discussion of the observations, a search for data was carried out to carry out a comparative discussion regarding the organization and existing routines in the sector. Thus, enabling a better understanding of the nature of the variables in order to develop arguments and propose solutions to the problem. The observation was to verify that supermarkets need improvements so that customers can be served in an appropriate and efficient manner. Assign a single employee responsible for the purchasing sector, in addition to employees who check the batches, the validity and if the products have any damage, are essential to ensure the quality of the products offered, as well as to ensure less rework in the organization of the supermarket shelves.
\end{abstract}

Keywords: Supermarkets; Quality control; Organization.

\section{Resumen}

El venta al por menor de Brasil sufre cambios todos los días con la intención de satisfacer las demandas de los consumidores. Los supermercados se reinventan cada día para que las necesidades visuales de la organización de las estanterías sean eficientes para los clientes y con ello aumenten su rentabilidad. El estudio se realizó en un supermercado de la ciudad de Muritiba - Bahía, entre septiembre y noviembre de 2019. La evaluación se realizó de 
manera cualitativa, a través de la observación de la vida diaria de un supermercado. Para la discusión de las observaciones se realizó una búsqueda de datos con el fin de realizar una discusión comparativa sobre la organización y las rutinas existentes en el sector. De esta forma, posibilita una mejor comprensión de la naturaleza de las variables con el fin de desarrollar argumentos y proponer soluciones al problema. La observación fue verificar que los supermercados necesitan mejoras para que los clientes puedan ser atendidos de manera adecuada y eficiente. Asignar un solo empleado responsable del sector de compras, además de los empleados que verifican los lotes, la vigencia y si los productos tienen algún desperfecto, son fundamentales para asegurar la calidad de los productos ofertados, así como para asegurar menos retrabajos en la organización de los estantes del supermercado.

Palabras clave: Supermercados; Control de calidad; Organización.

\section{Introdução}

O varejo brasileiro está sofrendo transformações ao longo do tempo por toda a competitividade no setor. No Brasil esse setor tem grande oferta de variedade de produtos para que possam atender as expectativas, desejo e necessidades dos consumidores. Para garantir sempre a singularidade, os mercados varejistas busca a cada dia ferramentas para melhorar o seu supermercado.

Segundo a norma da NBR ISO 22000:2019, segurança dos alimentos indica que o alimento não irá causar dano ao consumidor quando estiver sendo preparado e/ou consumido de acordo com o seu uso. Também relaciona os perigos físicos, químicos e biológicos ou as próprias condições do alimento com o potencial de causar efeito adverso (ABNT, 2019).

De acordo com Gomes (2007), um alimento seguro deve apresentar seus aspectos sensoriais desejáveis, propriedades nutricionais inerentes e estar, do ponto de vista sanitário, com total ausência ou tolerância de micro-organismos patogênicos e ausência de riscos físicos e químicos. A fiscalização para identificar a qualidade dos alimentos deve ser realizada não somente no produto final, mas em todas as etapas da produção, desde o abate ou colheita, passando pelo transporte, armazenamento e processamento, até a distribuição final ao consumidor (Silva, 1999).

Uma boa exposição dos itens a serem comercializados proporciona facilidade em encontrar os produtos nas gôndolas e atrai o cliente a caminhar mais pelo supermercado, aumentando as chances de vendas, mas por outro lado o arranjo físico em uma loja varejista afeta, diretamente, o desejo de compra do consumidor, na qual a dificuldade de encontrar os produtos e a inadequação do ambiente interno e equipamentos foram os principais motivos de insatisfação do cliente (Brito et al., 2017). Dessa maneira, é de grande relevância estudar o comportamento do consumidor devido a diversas influências como o preço e a qualidade dos produtos que podem gerar motivações e diversos estímulos que afetam seu comportamento de compra (Cruz et al., 2017)

Nessa direção Ferracciù (2007), ressalta que os produtos que estiverem ao alcance dos olhos e das mãos, têm maior a preferência por parte dos consumidores e maior rotatividade. Com uma boa exposição que valorize a marca e o produto, se torna mais propensa a compra mesmo que não seja necessária. Conforme Oliveira et al. (2007), além da correta exposição dos produtos, deve se criar condições que faça com que o consumidor circule por toda loja e por consequência, aumente a possibilidade de que ele realize compras por impulso, ou não planejadas.

Diante do exposto, objetivou-se avaliar a organização de produtos alimentícios em supermercado da cidade de Muritiba - Bahia

\section{Metodologia}

O estudo foi realizado em um supermercado da cidade de Muritiba - Bahia entre os meses de setembro a novembro de 2019. 
A avaliação foi realizada de forma qualitativa (Nunes, 2017), através da observação do dia a dia de um supermercado. Foi observado o processo de reposição, compra e organização dos produtos alimentícios nas prateleiras.

Para a discussão das observações foi realizada busca de dados para se realizar uma discussão comparativa referente a organização e rotinas existentes no setor. Desse modo, possibilitando o melhor entendimento da natureza das variáveis a fim de desenvolver argumentos e propor soluções para a problemática.

Após a observação crítica do setor, foi realizado um diálogo com alguns funcionários do supermercado, sendo que a equipe que compôs esta atividade foi formada por pessoas que são peças-chaves no processo de gerenciamento de compras e operações. O efeito principal da abordagem foi constatar as possíveis causas que acarretavam as perdas de cada um dos produtos do setor.

\section{Resultados e Discussão}

Durante o período de avaliação do supermercado foi constatado que a organização das mercadorias nas gondolas era realizada através do sistema de horizontalização, este sistema é formado por longas linhas de um mesmo produto em uma prateleira dando a impressão que só tem aquele produto. Com raras exceções, deve ser evitada, pois confunde visualmente (Barbosa et al., 2017; Azevedo, 2018).

Apesar de algumas contraindicações, Aragão (2006) ressalta em seu trabalho que há casos em que a exposição horizontal, quando se coloca o produto da mesma marca na mesma prateleira, consecutivamente, alinhando-os horizontalmente e, de preferência, à altura dos olhos e das mãos dos consumidores - valoriza o produto, melhorando sua rotação.

$\mathrm{Na}$ tentativa de valorizar o produto na exposição horizontal foi constatado que a organização das mercadorias nas gondolas era realizada de acordo com a marca, o que favorece a escolha dos consumidores. Ressalta-se que a exposição deve ser feita para vender produtos e não para satisfazer visualmente os encarregados de preparar a exposição (Aragão, 2006).

A exposição por marca tem se tornado uma estratégia nas gôndolas que acaba influenciando o poder de compra dos consumidores, tornando-se uma ferramenta essencial na gestão dos supermercados visto que é no ponto de venda que efetivamente acontece a decisão de compra (Rosa \& Dias, 2015).

A marca, para muitos consumidores, é um quesito de qualidade que por conseguinte é um conceito inerente a essência do ser humano. Por isso, seu conceito é tão difícil, pois, cada consumidor pode ter o seu seja relacionado ao produto ou ao serviço. Serralvo (2004), relata que se trata de uma busca pela satisfação pessoal, social e anseio por segurança, muitas vezes interpretados como a garantia de sucesso prometida por uma marca, onde ele identificou ainda que uma das interpretações da busca pela realização consiste em expressar o poder financeiro "de se comprar o que se quer, e não o que se pode".

Esta escolha de produtos pela marca, segundo Freitas e Pereira (2013), supera a qualidade nutricional ou a tipologia do alimento como os atributos de maior importância pelo grupo pesquisado.

Nas gôndolas do supermercado assim como nos freezers, os produtos de marcas líderes ou produtos com maior margem de lucratividade ficavam à altura dos olhos dos clientes, ou, ao menos, em lugar de maior visibilidade. Já na parte inferior normalmente havia produtos mais baratos e de menor lucratividade, mas produtos responsáveis pelo aumento do mix e da oferta de mercadorias aos consumidores.

No entanto, foi observado que por diversas vezes nos freezer, a organização dos frios (iogurtes, queijos, presunto, margarinas, requeijão e salames), apesar de possuir uma certa padronização, era realizada de modo aleatório por qualquer funcionário do estabelecimento disponível no momento, ou pelo próprio representante da marca do produtos, que no caso dos iogurtes, seguiam o protocolo da empresa onde as marcas de maior valor agregado ficam nas primeiras prateleiras e as de menor valor ficam nas prateleiras inferiores. 
A posição dos produtos nas gôndolas deve ser pensada de forma estratégica e não aleatoriamente, de modo que o gerenciamento desta resulte no aumento das vendas de modo a maximizar o ganho, podendo ser aplicada no ponto de venda como um todo e em todas as categorias de produtos (Rosa \& Dias, 2015).

É válido ainda salientar que para muitos consumidores com poder de decisão, o risco de ver a família consumir um produto cuja percepção de qualidade seja inferior, assim como a sensação de que se está desperdiçando dinheiro ao adquirir algo de qualidade inferior, conduz o consumidor à compra de marcas líderes, apesar de seu preço mais alto (Serralvo, 2004). Em seu trabalho Dos Santos et al., (2020), conclui que a compra de produtos de marca em detrimento da autoestima, e por isso a compra de produtos de luxo está diretamente relacionada à comparação que realizam com as pessoas a sua volta.

No processo de precificação do estabelecimento observado foi identificado que os preços eram inseridos de modo manual e sem boa visibilidade, tanto no produto como nas gôndolas. Alguns clientes reportavam dificuldades quanto ao tamanho da etiqueta, a diferença de preço de produtos ao chegar ao caixa e ainda a falta de preço em algumas mercadorias.

Ao realizar um estudo sobre a satisfação do consumidor com o setor supermercadista Réveillion (1998), observou que as pessoas reclamam que é mais difícil localizar o preço do produto na gôndola do que na própria embalagem, principalmente no caso das pessoas mais idosas que não enxergam tão bem.

Ainda em relação à precificação dos produtos, a inserção de etiquetas proporcionais com as escritas maiores para que venha atender melhor aos clientes, principalmente idosos e clientes com dificuldade visual, de modo que todos tenham uma boa visibilidade dos preços, que é um fator importante para os compradores, e que torna o processo de compra mais cómodo (Rocha, 2017).

Quando não é bem realizada, pode causar prejuízos, já que quando um produto é mal precificado ou foi precificado certo, mas se encontra em local errado, o cliente se sente enganado e pode exigir levar o produto pelo valor que estava sinalizado, o que pode gerar a devolução do dinheiro e insatisfação do consumidor (Barbosa et al., 2017).

Foi identificado que o supermercado não possuía um setor específico de compras, o gerente geral acumulava diversas funções na empresa e dentre elas a de comprador, o que gerava uma série de implicações negativas na rotina. Uma destas implicações se dava pelo fato de que às mercadorias expostas aos clientes eram acumuladas com muitos produtos nas gôndolas, decorrente de diversos pedidos de compras realizados pelo gerente com fornecedores diferentes, o que por conseguinte gerava produtos com shelf lifes sem padrão. De modo geral, os produtos que eram expostos nas gôndolas continham um shelf life maior do quer os novos produtos que chegavam, gerando um transtorno no estabelecimento, soma se ainda o fato de que os repositores reorganizavam as prateleiras fazendo com que coubesse tudo naquele espaço destinado para cada produto.

A verificação dos shelf lifes dos produtos era constante nas gôndolas do supermercado, pois por pequenos detalhes os consumidores podem comprar sem perceber que estão fora da validade. Ao ser constatado que determinado produto estava fora do prazo de validade estabelecido era retirado das prateleiras e levado ao local apropriado para fazer a troca com a distribuidora responsável. Quanto a este quesito, é muito importante o treinamento dos colaboradores que atualmente não é realizado e para isto Dogo et al. (2013), sugerem esta ação constantemente, e um tempo maior dispensado por eles ao serviço de conferência das datas de validade, assim como a criação constante de brigadas de validade nestes departamentos de maior ocorrência.

O processo de recolhimento de mercadorias nas prateleiras poderia ser evitado na rotina do supermercado caso houvesse um procedimento de verificação dos lotes no ato do recebimento dos produtos. Para Souza et al. (2016), este é de suma importância para a organização de empresas, sendo necessários para que o supermercado tenha controle com os produtos que estão vencidos ou a vencer, bem como programar o recebimento de mais produtos, evitando acumular itens desnecessários e prejuízos ocasionados por produtos vencidos. 
No supermercado avaliado, os repositores possuíam uma seção especifica para realizar suas atividades que eram organizadas pelo responsável. E isto gerava dificuldades entre eles na reposição das respectivas mercadorias pois, quando ocorria falta de funcionário por motivo de férias ou outros motivos, o setor passava por dificuldades de reposição. Quanto a isto, Gonçalves et al. (2020), ressaltam a necessidade em treinamentos para todos os funcionários a fim de não acontecer problemas de manuseio dos produtos e desordem no ambiente gerando possíveis custos desnecessários para a empresa em questão, além do mais, com investimento em layout espera-se que o consumidor fique mais tempo na loja e se atente para produtos que não estavam previstos em suas compras (Napoleão, 2017).

Quanto a iluminação e ventilação do espaço de compra, o supermercado analisado carece de melhorias, no primeiro por utilizar iluminação mista, ou seja, parte natural e parte artificial com o intuito de realizar economia de energia elétrica, o dificulta em alguns momentos do dia a boa visualização dos produtos nas gôndolas, já para a ventilação, em vários dias do ano, a temperatura do ambiente se torna desagradável por não apresentar sistema de climatização, tornando assim o ambiente desconfortável para o cliente. A soma de má iluminação e desconforto térmico constrói um ambiente totalmente insalubre para o cliente possa permanecer por maior tempo, o que por conseguinte poderá acarretar menores vendas, além do mais a iluminação é importante para acabar com a obscuridade do ambiente, denotando a ideia de que algo está escondido, e não visível (Almeida, 2013).

Para Almeida (2013), uma boa iluminação evoca a noção de limpeza e transparência, despertando a confiança e a sensação de bem-estar do cliente. Duong, (2016), ao entrevistar gestores de supermercados, informaram que iluminação, limpeza, lotação e pessoal são os pontos mais importantes para a satisfação do cliente, enquanto limpeza, vitrines e pessoal são os principais influenciadores do comportamento de compra dos clientes.

De modo geral, Feijó e Botelho (2012), apontaram em seu estudo que a percepção da falta de organização provoca manifestações de extremo desconforto, afetando negativamente as emoções inclusive do consumidor.

No entanto, quando as experiências de compra são positivas, tendem a possuir intenções de recompra com o mesmo varejista de forma positiva (Alves et al., 2018).

\section{Conclusão}

Com base no que foi exposto verifica-se a necessidade de realizar algumas melhorias para atender adequadamente os seus clientes, e com isso obter boas vendas. Destinar um único colaborador responsável pelo setor de compras, além de colaboradores que confiram os lotes, a validade e se os produtos possuem alguma avaria, são imprescindíveis para garantir a qualidade dos produtos oferecidos, bem como garantir um menor retrabalho na organização das gôndolas do supermercado.

Para melhor o funcionamento do estabelecimento é necessário uma rotatividade entre os repositores, solucionando assim a falta de colaboradores no estabelecimento, esta rotatividade poderia ser bimestral para que os repositores possam ter contato com todos os setores de modo que não haja dificuldades quando houver a falta de funcionário no setor.

A de se pontuar que, melhorias imediatas na iluminação e no sistema de ventilação, poderão deixar os consumidores mais à vontade para transitar pelos corredores levando-os a uma compra mais satisfatória gerando mais lucros ao supermercado.

Como abordagem para trabalhos futuros, poderemos avaliar o layout e a organização das gôndolas no que tange a acessibilidade de pessoas portadoras de necessidades especiais, estas não conseguem ter total autonomia e independência nas escolhas de seus produtos principalmente em supermercados de cidades do interior do estado, onde a maior dificuldade se inicia na entrada do estabelecimento. 


\section{Referências}

Associação Brasileira de Normas Técnicas-ABNT. (2006). Sistemas de gestão da segurança de alimentos: requisitos para qualquer organização na cadeia produtiva de alimentos. ABNT.

Almeida, W. T., (2013). Análise das estratégias de merchandising utilizadas em supermercado de varejo: um estudo de caso no Hiper Queiroz. Monografia (Bacharel em Comunicação Social, com habilitação em Publicidade e Propaganda). Universidade do Estado do Rio Grande do Norte. Faculdade de Filosofia e Ciências Sociais.

Alves, C. A., Stefanini, C. J., da Silva, L. A., \& do Amaral Moretti, S. L. (2018). O papel da experiência de compra na intenção de recompra. Revista Ciências Administrativas, 24(2).

Aragão, R. K. P. A.; (2006). A promoção de vendas no Brasil e na empresa Unilever. TCC (especialização) - Universidade Federal do Ceará, Faculdade de Economia, Administração, Atuária e Contabilidade - FEAAC, Centro de Treinamento e Desenvolvimento - CETREDE, Curso de Especialização em Estratégia e Gestão Empresarial, Fortaleza-CE.

Azevedo, I. H. C. D. (2018). Merchandising em ponto de venda: um estudo de caso na Redemais. (Bachelor's thesis, Universidade Federal do Rio Grande do Norte).

Barbosa, M. A. F., de Almeida Neto, A. A., \& França, J. (2017). 06) Visual Merchandising: Teoria e Prática-Ultrapassando os Limites de uma Sala de Aula. Revista Brasileira de Gestão e Engenharia| RBGE|, (15), 111-132.

Brito, G. D.; Neto Lima, E. G. ; Ribeiro, V. S.; \& Brandão, R. F. S. (2017). A influência do layout na comercialização em um mercado de médio porte. In: XXXVII Encontro Nacional de Engenharia de Produção, Joinville (SC). Anais Eletrônicos do Encontro Nacional de Engenharia de Produção. Rio de Janeiro (RJ): ABEPRO,37.

Cruz, G. F. R.; Ferreira, M. C. O.; Silva, J. G.; \& Cucato, J. S.T. (2017). O comportamento do consumidor de alimentos funcionais. In: VI SINGEP - Simpósio Internacional de Gestão de Projetos, Inovação e Sustentabilidade, São Paulo. VI SINGEP - Simpósio Internacional de Gestão de Projetos, Inovação e Sustentabilidade

Dogo, L. A., Fornari, J. V., Bernabe, A. S., Arçari, D. P., Ribeiro, R., \& Ferraz, N. (2013). Ocorrência de produtos fora da validade em gôndolas de hipermercados da grande São Paulo-SP. Saúde em Foco, 7(5), 35-40.

Dos Santos, M. R. K., Ferreira, M. C. O., Bizarrias, F. S., Cucato, J. D. S. T., \& da Silva, J. G. (2020). Percepção de luxo na Classe C versus classe alta. O papel da identidade e autoestima. Revista de Administração Unimep, 18(2), 236-256.

Duong, Q. B. (2016). The influence of store environment on customer satisfaction across different customer demographic segmentations within Australian supermarkets (Doctoral dissertation, Southern Cross University).

Ferracciù, J. D. S. S. (2007). Marketing promocional. Pearson Educación.

Feijó, F. R., \& Botelho, D. (2012). Efeito dos fatores de merchandising nas vendas do varejo. RAE-Revista de Administração de Empresas, 52(6), 628-42.

Freitas, A. A. F.; \& Pereira, M. C. (2013). Influência das Informações Nutricionais na Escolha de Produtos Alimentícios: uma Aplicação da Técnica de Análise Conjunta. PMKT - Revista Brasileira de Pesquisas de Marketing, Opinião e Mídia, 13(14),186-199.

Gonçalves, J. C.; Moser, F.; Cordova, R. A.; \& Dias, R. H. A. (2020). A importância da gestão de estoque em um supermercado. Synthesis (Lages), 1 (10), 104-113.

Gomes, J. C. (2011). Legislação de alimentos e bebidas. In Legislação de alimentos e bebidas (663-663).

Napoleão, T. (2017). A Influência do Layout de um" Atacarejo" na Decisão de Compra do Consumidor: Estudo realizado em uma loja da grande Florianópolis. Trabalho de Conclusão de Curso. Centro Socioeconômico, Departamento de Ciências da Administração, UFSC. Florianópolis-SC,

Nunes, P. T. (2018). Finanças Pessoais: Um estudo de caso em uma Instituição Religiosa. Revista de Administração e Contabilidade da FAT, 9 (3).

Révillion, A. S. P. (1998). Um estudo sobre a satisfação do consumidor com o setor supermercadista em Porto Alegre. Tese de Doutorado. Dissertação (Mestrado em Administração) - Setor de Ciências Sociais Aplicadas-Programa de Pós-Graduação em Administração, Universidade Federal do Rio Grande do Sul, Porto Alegre.

Rocha, C. R. (2017). Merchandising num supermercado Pingo Doce (Master's thesis).

Rosa, N. G., \& Dias, S. D. B. A. (2015). Estratégia E Gestão Das Gôndolas De Supermercado. Estudos, 42(1), 83-102.

Serralvo, F. A., \& Ignacio, C. P. (2004). O comportamento do consumidor de produtos alimentícios: um estudo exploratório sobre a importância das marcas líderes. VII SEMEAD, 473-480.

Silva, J. A. (1999). As novas perspectivas para o controle sanitário dos alimentos. Higiene alimentar, 19-25.

Souza, I., Santos, I., Monteiro, A., Barbosa, M., \& Izoldi, N. (2016). Sistema integrado de gestão de estoque e armazenagem: estudo de caso em um supermercado de pequeno porte. XIII Simpósio de Excelência em Gestão e Tecnologia-SEGET. Resende, RJ. 